\title{
Design and control of permanent magnet assisted synchronous reluctance motor with copper loss minimization using MTPA
}

\author{
Songklod Sriprang ${ }^{1,6}$, Babak Nahid-Mobarakeh ${ }^{1}$, Noureddine Takorabet $^{1}$, \\ Serge Pierfederici ${ }^{2}$, Poom Kumam ${ }^{3}$, Nicu Bizon ${ }^{4}$, Nesser Taghavi ${ }^{5}$, \\ Abolfazl Vahedi ${ }^{5}$, Pongsiri Mungporn ${ }^{6}$, Phatiphat Thounthong ${ }^{6 *}$
}

\begin{abstract}
It is necessary to find the suitable $d$ - and $q$-axis reference currents to control PMA-SynRM motors with high efficiency. This paper presents the maximum torque per ampere (MTPA) to minimize the copper losses of the system and utilizes the field weakening control to operate above the rated speed of the PMA-SynRM. The copper losses equation and electromagnetic torque are used to optimize the $d$ - and $q$-axis current references. A small-scale $1 \mathrm{~kW}$ prototype PMA-SynRM was designed and manufactured to test and examine the proposed control in the laboratory. The proposed algorithm was digitally carried out using the MicroLab Box dSPACE. The simulation results show that the copper losses of the machine with the MTPA algorithm are lower than those without the MTPA algorithm. The PMA-SynRM operates above the base speed of $\sim 70 \%$ in the constant power region by mean of field weakening control.
\end{abstract}

K e y w o r d s: copper loss, permanent-magnet assisted reluctance motor (PMA-SynRM), maximum torque per ampere (MTPA), field weakening, PI linear control

\section{Introduction}

Permanent-magnet synchronous motors (PMSMs) are the most popular motors in automotive applications such as electric vehicles (EVs) and hybrid electric vehicles (HEVs). They have a high torque density, high power density, wide speed range, and high efficiency because rare-earth permanent magnets (PMs), such as $\mathrm{NdFeB}$, are mounted on the rotor $[1,2]$. However, rare-earth elements used in electric vehicles are costly, and there are concerns about the supply chain and trade war as well as resource monopoly. A new machine called permanent-magnet assisted synchronous reluctance motor (PMA-SynRM) has been designed by reducing many PMs or using ferrite magnets in the rotor to avoid such circumstances. The PMA-SynRM is more effective than the SynRM [3-5]. Besides, its price is much lower than that of the conventional PMSM because ferrite PMs are cheaper than rare-earth PMs. The PMA-SynRM is the most promising rare-earth-free machine for the next generations of EVs and HEVs. Figure 1 illustrates the structure proposed for a four-pole PMA-SynRM with a ferrite magnet and the reference $d$ - and $q$-axes. The difference between the PMA-SynRM and traditional PMSM is that the PMs are inserted in the flux barriers of the rotor.
Therefore, the magnetization occurs along the negative $q$-axis. The PMA-SynRM design and control have been proposed in several publications. Most of the research focused on the rotor's geometry based on machine design and optimization aspects $[6-10]$ as well as the PM element [11-13]. Potential control methodology has been discussed in recent literature [14]. Thounthong et al [15] dealt with the differential flatness based control for the PMSM drive with the nonlinear observers. Trancho et al [16] proposed a robust control algorithm for the PMSynRMs in EVs and HEVs. They used a nonlinear control based on second-order SMC current regulators to control the current loop and utilized the lookup table for speed loop control conditions. Although a suitable control of PMA-SynRMs has been introduced in previous publications, it remains challenging to obtain a control system with high-performance due to conditions such as copper loss and vast speed operation.

In this paper, a small-scale prototype PMA-SynRM with a ferrite magnet was designed and manufactured for laboratory tests [17]. The control scheme was carried out using a PI-controller-based field-oriented vector control (FOC). The copper losses were minimized using the MTPA. The machine can be operated above the rated speed by utilizing the field-weakening (FW) control. Fi-

\footnotetext{
${ }^{1}$ Green-ENSEM Laboratory, Université de Lorraine, 2 Avenue de la foret de haye, BP 90161Vandoeuvre-les-Nancy, Lorraine 54505 France l: songklod.sriprang@univ-lorraine.fr, babak.nahidmobarakeh@univ-lorraine.fr, noureddine.takorabet@univ-lorraine.fr. ${ }^{2}$ LEMTA Laboratory, Université de Lorraine, 2 Avenue de la foret de haye, BP 90161Vandoeuvre-les-Nancy, Lorraine 54505 France, serge.pierfederici@univ-lorraine.fr, ${ }^{3}$ Theoretical and Computational Science Center, Faculty of Science, King Mongkuts University of Technology Thonburi, Bangkok 10140, Thailand, poom.kumam@mail.kmutt.ac.th, ${ }^{4}$ Faculty of Electronics, Communications and Computers, University of Pitesti, Arges 110040, Pitesti, Romania, nicu.bizon@upit.ro ${ }^{5}$ University of Science and Technology, Tehran, Iran ${ }^{6}$ Renewable Energy Research Centre, Department of Teacher Training in Electrical Engineering, Faculty of Technical Education, King Mongkut's University of Technology North Bangkok, Bangkok 10800, Thailand, * Corresponding author: phatiphat.t@fte.kmutnb.ac.th
} 


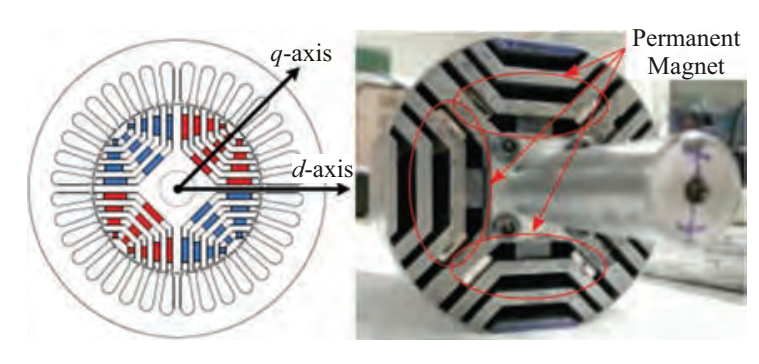

Fig. 1. Rotor structure of the case study PMA-SynRM

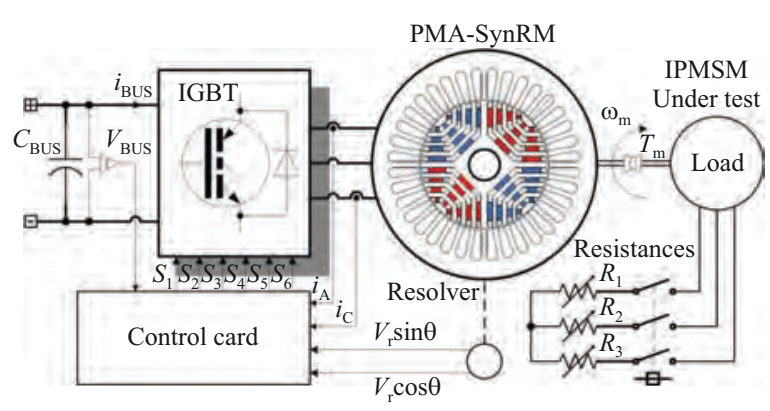

Fig. 2. Three-phase inverter driving the PMA-SynRM, where $V_{\mathrm{BUS}}, i_{\mathrm{BUS}}, i_{\mathrm{A}}$ and $i_{\mathrm{C}}$ are the $\mathrm{DC}$ bus voltage, input inverter current, and motor phase currents respectively

Table 1. PMA-SynRM Parameters Based on FEM Analysis

\begin{tabular}{lcc}
\hline Symbol & Meaning & Value \\
\hline$\Psi_{\mathrm{m}}$ & Permanent magnet flux & $0.138 \mathrm{~Wb}$ \\
$L_{\mathrm{d}}$ & Normal $d$-axis inductance & $288 \mathrm{mH}$ \\
$L q$ & Normal $q$-axis inductance & $38 \mathrm{mH}$ \\
$L_{\mathrm{dq}}$ & Mutual inductance & $4 \mathrm{mH}$ \\
\hline
\end{tabular}

nally, a full-scale control system test bench driving the PMA-SynRM was implemented to validate the developed control scheme.

\section{Permanent magnet assisted synchronous motor model and proposed control development}

\subsection{Mathematic models of PMA-SynNRM/inverter}

A three-phase inverter (Fig. 2) provides a three-phase AC voltage source using sinusoidal pulse width modulation (SPWM. The stator-voltage and flux linkage equations of the PMA-SynRM in the $d-q$ reference frame can be expressed as follows $[15,17]$

$$
\begin{aligned}
& v_{\mathrm{d}}=R_{\mathrm{s}} i_{\mathrm{d}}+\frac{\mathrm{d} \Psi_{\mathrm{d}}}{\mathrm{d} t}-\omega_{\mathrm{e}} \Psi_{\mathrm{q}}, \\
& v_{\mathrm{q}}=R_{\mathrm{s}} i_{\mathrm{q}} \frac{\mathrm{d} \Psi_{\mathrm{q}}}{\mathrm{d} t}+\omega_{\mathrm{e}} \Psi_{\mathrm{d}},
\end{aligned}
$$

where $R_{\mathrm{s}}$ is the resistance (or system losses), $i_{\mathrm{d}}$ and $i_{\mathrm{q}}$ are $d$ - and $q$-axis currents and $\Psi_{\mathrm{d}}$ and $\Psi_{\mathrm{q}}$ are $d$ and $q$-axis flux-linkage, respectively

$$
\omega_{\mathrm{e}}=n_{\mathrm{p}} \omega_{\mathrm{m}},
$$

where $\omega_{\mathrm{e}}, \omega_{\mathrm{m}}, n_{\mathrm{p}}$, are electrical angular frequency, mechanical angular frequency, number of pole pairs respectively.

The flux linkage equations are

$$
\Psi_{\mathrm{d}}=L_{\mathrm{d}} i_{\mathrm{d}}, \quad \Psi_{\mathrm{q}}=L_{\mathrm{q}} i_{\mathrm{q}}-\Psi_{\mathrm{m}}
$$

where $\Psi_{\mathrm{m}}$ is the permanent magnet flux.

By substituting (4) and (5) into (1) and (2), the current equations can be derived

$$
\begin{aligned}
& \frac{\mathrm{d} i_{\mathrm{d}}}{\mathrm{d} t}=\frac{1}{L_{\mathrm{d}}}\left(v_{\mathrm{d}}-R_{\mathrm{s}} i_{\mathrm{d}}+\omega_{\mathrm{e}} L_{\mathrm{q}} i_{\mathrm{q}}-\omega_{\mathrm{e}} \Psi_{\mathrm{m}}\right) \\
& \frac{\mathrm{d} i_{\mathrm{q}}}{\mathrm{d} t}=\frac{1}{L_{\mathrm{q}}}\left(v_{\mathrm{q}}-R_{\mathrm{s}} i_{\mathrm{q}}+\omega_{\mathrm{e}} L_{\mathrm{d}} i_{\mathrm{d}}\right) .
\end{aligned}
$$

The produced electromagnetic torque of the PMA-SynRM expressed in the $d-q$ reference frame can be expressed as follows

$$
T_{\mathrm{e}}=n_{\mathrm{p}}\left(\Psi_{\mathrm{d}} i_{\mathrm{q}}-\Psi_{\mathrm{q}} i_{\mathrm{d}}\right) .
$$

Substituting (4) and (5) into (8), it yields

$$
T_{\mathrm{e}}=n_{\mathrm{p}} i_{\mathrm{d}}\left(\left(L_{\mathrm{d}}-L_{\mathrm{q}}\right) i_{\mathrm{q}}+\Psi_{\mathrm{m}}\right),
$$

where $L_{\mathrm{d}}$ and $L_{\mathrm{q}}$ are $d$-and $q$-axis, and $T_{\mathrm{e}}$ is produced electromagnetic torque.

\subsection{FEM-Based Magnetic Model}

Because of the crucial roles of the $L_{\mathrm{d}}$ and $L_{\mathrm{q}}$ inductances in the overload capability, the field-weakening range was improved, and precise control was established to calculate the direct and quadrature inductances. The $d q$ inductances were calculated in the nonlinear case in which the saturation of the stator teeth and rotor ribs are considered. The saturation effects of the $d$ and $q$ inductances can be calculated using the ratio between the flux linkage variations and the slight increase in the $d$ - and $q$-axes current, as expressed in (10), (11), and (12), [18]. The effect of cross-coupling due to saturation was studied for this machine. The parameters were identified in the $d-q$ frame. The current supply conditions were simulated, and the flux linkages were evaluated by integrating the magnetic vector potential. The $d$ - and $q$-flux linkages related to the $d$ - and $q$-axes currents based on FEM analysis are represented in Fig. 3. Figure 3(a) shows the flux linkage in the $d$ reference frame $\Psi_{d}\left(i_{\mathrm{d}}, i_{\mathrm{q}}\right)$ and Fig. 3(b) shows the flux linkage in the $q$ reference frame $\Psi_{q}\left(i_{\mathrm{d}}, i_{\mathrm{q}}\right)$ - Table 1 provides the flux linkages of the PMs and $d-q$ inductances of the linear control system design

$$
\begin{gathered}
L_{\mathrm{d}}=\frac{\partial \Psi_{\mathrm{d}}\left(i_{\mathrm{d}}, i_{\mathrm{q}}\right)}{\partial i_{\mathrm{d}}}=\left.\frac{\Delta \Psi_{\mathrm{d}}\left(i_{\mathrm{d}}, i_{\mathrm{q}}\right)}{\Delta i_{\mathrm{d}}}\right|_{i_{\mathrm{q}}=\mathrm{const}}, \\
L_{\mathrm{q}}=\frac{\partial \Psi_{\mathrm{q}}\left(i_{\mathrm{d}}, i_{\mathrm{q}}\right)}{\partial i_{\mathrm{q}}}=\left.\frac{\Delta \Psi_{\mathrm{d}}\left(i_{\mathrm{d}}, i_{\mathrm{q}}\right)}{\Delta i_{\mathrm{q}}}\right|_{i_{\mathrm{d}}=\mathrm{const}}, \\
L_{\mathrm{dq}}=\frac{\partial \Psi_{\mathrm{d}}\left(i_{\mathrm{d}}, i_{\mathrm{q}}\right)}{\partial i_{\mathrm{q}}}=\left.\frac{\Delta \Psi_{\mathrm{d}}\left(i_{\mathrm{d}}, i_{\mathrm{q}}\right)}{\Delta i_{\mathrm{q}}}\right|_{i_{\mathrm{d}}=\mathrm{const}} .
\end{gathered}
$$



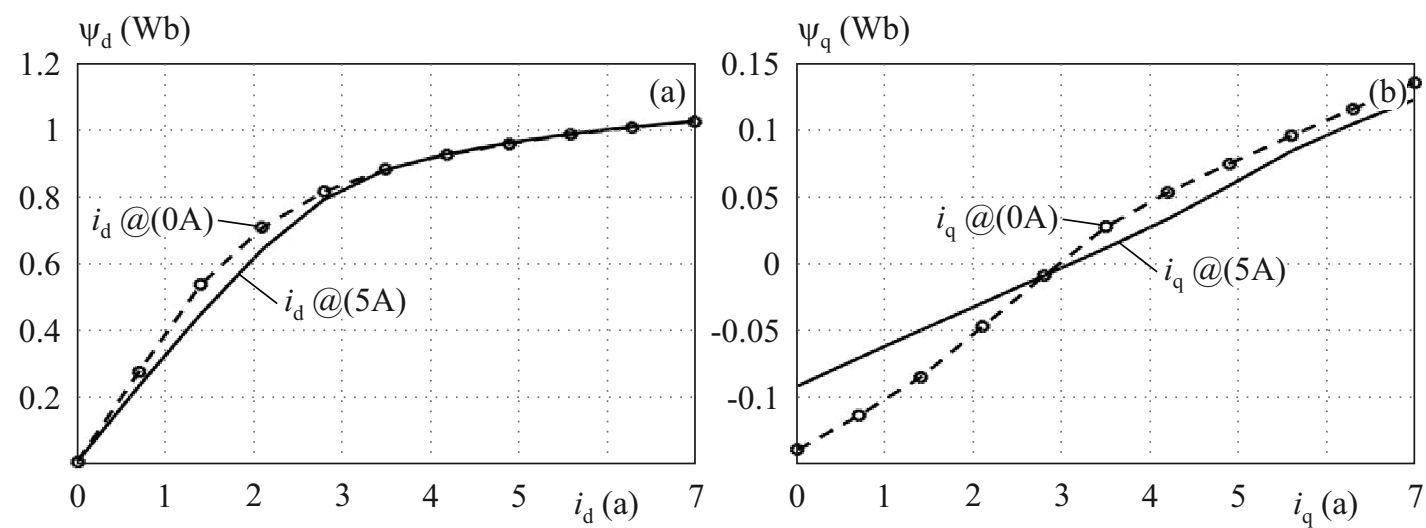

Fig. 3. (a) $-\Psi_{\mathrm{d}}\left(i_{\mathrm{d}}, i_{\mathrm{q}}\right)$ as function of $i_{\mathrm{d}}$ and $i_{\mathrm{q}},(\mathrm{b})-\Psi_{\mathrm{q}}\left(i_{\mathrm{d}}, i_{\mathrm{q}}\right)$ as function of $i_{\mathrm{d}}$ and $i_{\mathrm{q}}$

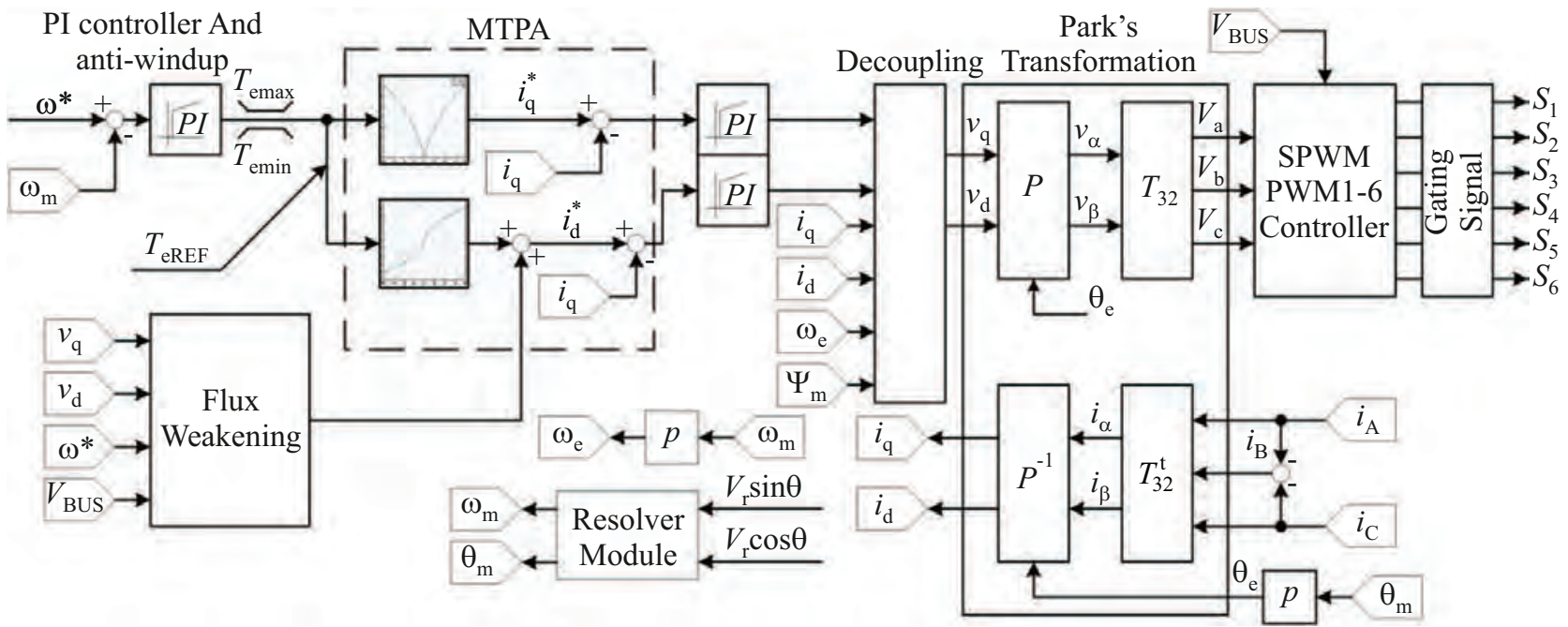

Fig. 4. Proposed control block diagram

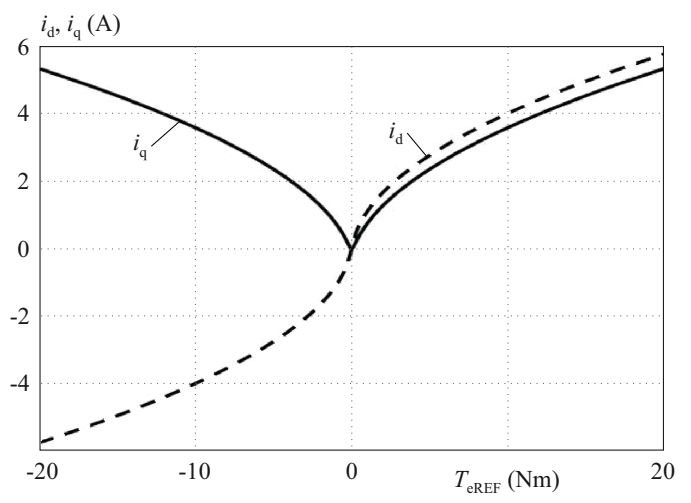

Fig. 5. The given MTPA curve for $i_{\mathrm{d}}$ and $i_{\mathrm{q}}$ references

\subsection{MTPA for copper loss minimization}

Based on the torque equation (9), the torque of the PMA-SynRM can be divided into two types: one is produced by the permanent-magnet flux (interaction torque) and the other is produced by the difference in the inductances of the $d q$ axes (reluctance torque). Therefore, to minimize the copper losses and increase the overall performance of the machine, the MTPA was used. The copper loss equation is

$$
P_{\mathrm{Cu}}=R_{\mathrm{s}}\left(i_{\mathrm{d}}^{2}+i_{\mathrm{q}}^{2}\right)
$$

As shown in Fig. 4 and referring to (9), the reference torque equation can be written as

$$
T_{\mathrm{eREF}}=n_{\mathrm{p}}\left(\Delta L i_{\mathrm{q}}+\Psi_{\mathrm{m}}\right) i_{\mathrm{d}},
$$

where $\left.\Delta L=L_{\mathrm{d}}-\mid l q\right)$ is the difference of inductances.

Based on (14) and the reference torque of the PMASynRM, there is no reference torque if the direct current is set to zero $\left(i_{\mathrm{d}}=0\right)$. In contrast, the reference torque is equal to the interaction torque if the quadrature current is zero $\left(i_{\mathrm{q}}=0\right)$. Therefore, in order to satisfy torque reference, the quadrature current $i_{\mathrm{q}}$ and direct current $i_{\mathrm{d}}$ must be minimized by using the MTPA concept. As shown in Fig. 4, the minimum current vectors are stored in lookups consisting of lookup tables for the $i_{\mathrm{q}}$ and $i_{d}$ references. However, to obtain the MTPA curve for the PMA-SynRM, the current vectors are subjected to the following conditions

$$
\begin{array}{ll}
\max : & T_{\mathrm{eREF}}=n_{\mathrm{p}} i_{\mathrm{d}}\left(\Delta L i_{\mathrm{q}}+\Psi_{\mathrm{m}}\right) \\
\min : & P_{\mathrm{Cu}}=R_{\mathrm{s}}\left(i_{\mathrm{d}}^{2}+i_{\mathrm{q}}^{2}\right) .
\end{array}
$$

The quadrature current $i_{\mathrm{q}}$ can be obtained by using (14)

$$
i_{\mathrm{d}}=\frac{T_{\mathrm{eREF}}}{n_{\mathrm{p}}\left(\Delta L i_{\mathrm{q}}+\Psi_{\mathrm{m}}\right)} .
$$



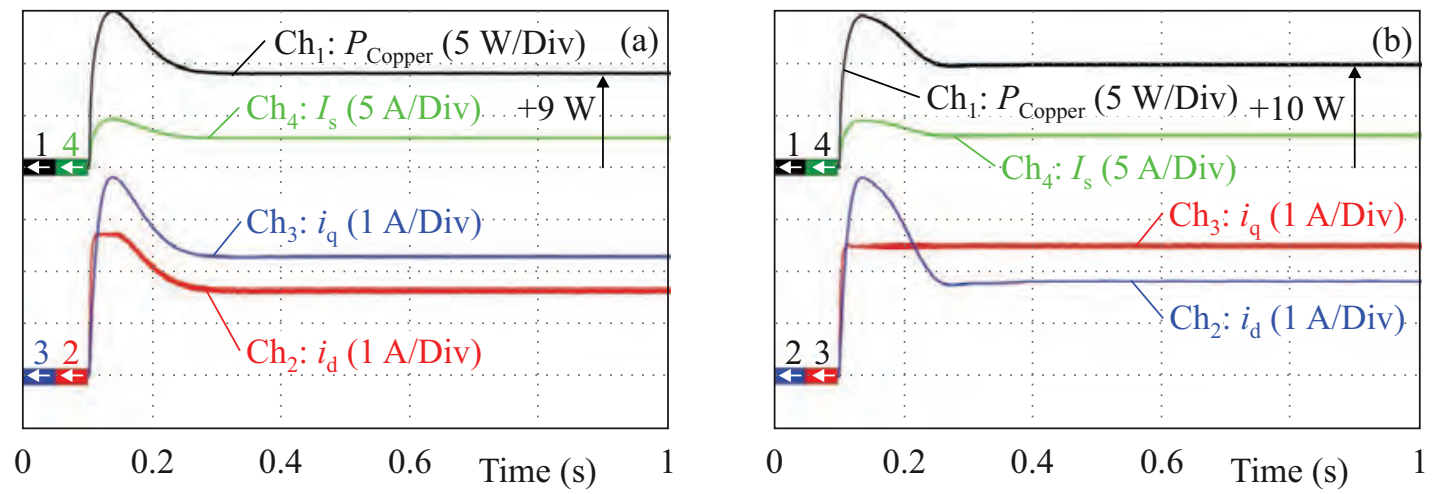

Fig. 6. Simulation of the copper losses(a)- with, and (b)- without MTPA

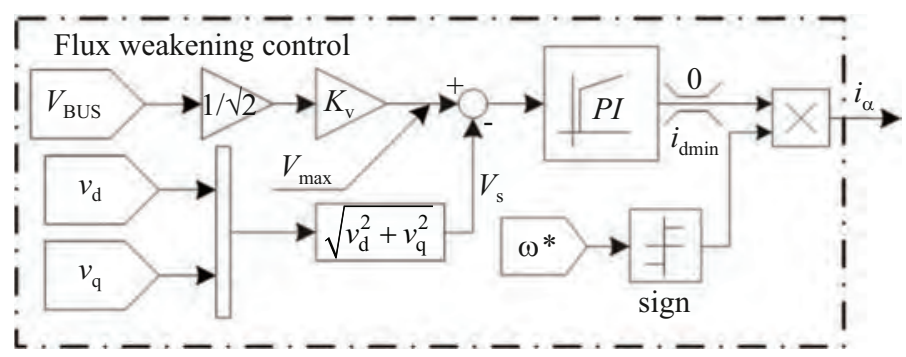

Fig. 7. Block diagram of the proposed field-weakening control

By substituting (16) into (13), the copper loss equation can be obtained

$$
P_{\mathrm{cu}}\left(i_{\mathrm{q}}\right)=R_{\mathrm{s}}\left[\left(\frac{T_{\mathrm{eREF}}}{n_{\mathrm{p}}\left(\Delta L i_{\mathrm{q}}+\Psi_{\mathrm{m}}\right)}\right)^{2}+i_{\mathrm{q}}^{2}\right] .
$$

To obtain the MTPA curve of $i_{\mathrm{q}}$, the derivative of the copper loss (17) with respect to $i_{\mathrm{q}}$ can be expressed by using (18) assuming $\Delta L$ is a constant parameter. As shown in Fig. 5, the $T_{\text {eREF }}$ is considered as a constant value in order to obtain the given $i_{\mathrm{d}}$ and $i_{\mathrm{q}}$ references

$$
\begin{aligned}
& \left.\frac{\mathrm{d} P_{\mathrm{Cu}}}{\mathrm{d} i_{\mathrm{q}}}\right|_{i_{\mathrm{q} \text { opt }}}=0 \\
& i_{\mathrm{q} \mathrm{opt}}=\frac{T_{\mathrm{eREF}}^{2}}{n_{\mathrm{p}}^{2}} \frac{\Delta L}{\left(\Psi_{\mathrm{m}}+\Delta L i_{\mathrm{q} \mathrm{opt}}\right)^{3}},
\end{aligned}
$$

where $i_{\mathrm{q} \text { opt }}$ is the optimum quadrature current.

Using numerical Newton-Raphson method,

$$
x_{i+1}=x_{i}-\frac{f\left(x_{i}\right)}{f^{\prime}\left(x_{i}\right)},
$$

where $x_{i+1}$ is the next optimum point, the MTPA curve can be obtained, see Fig. 5 .

Control algorithm is shown in Fig. 6(a) and Fig. 6(b), respectively. Based on the copper loss (13), the signal is illustrated as Ch1 in both figures. In the case of the control system without MTPA, the quadrature current $i_{\mathrm{q}}$ is set to $2.5 \mathrm{~A}$. The results show that the copper losses of the control system with the MTPA algorithm are lower than those of the control system without MTPA of $\approx$ $10 \%$.

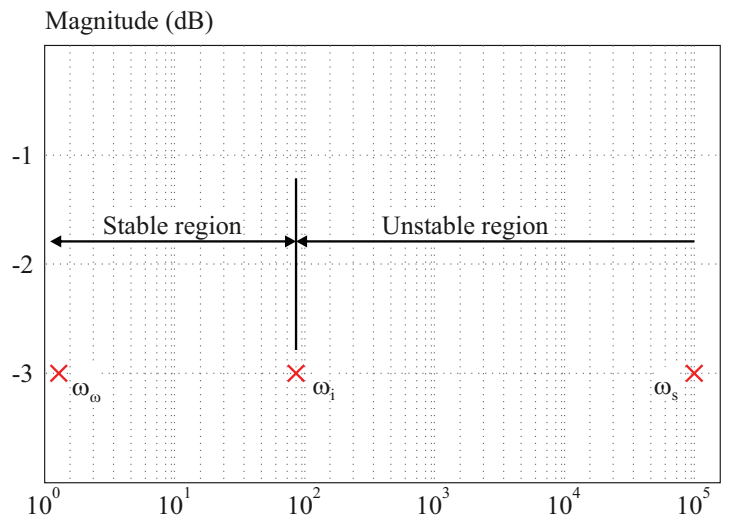

Fig. 8. Setting of the controllers by choosing the crossover frequency in the frequency space

\subsection{Field-weakening control for the constant power region operation}

As shown in Fig. 7, the maximum voltage $V_{\max }$ is the voltage that can be supplied by the three-phase inverter to the machine. It is restricted by the DC bus voltage $V_{\mathrm{BUS}}$ and PWM technique. The proposed field-weakening algorithm is a simple scheme and easy to implement. It does not depend on the PMA-SynRM model in contrast to previous publications $[19,20]$. The concept of the proposed algorithm is that if the stator voltage $V_{\mathrm{s}}$ increases and reaches the maximum voltage $V_{\max }$, the direct current decreases proportional to the difference between the 
two voltages. Therefore, $V_{\mathrm{s}}$ is restricted as follows

$$
V_{\mathrm{s}}=\sqrt{v_{\mathrm{d}}^{2}+v_{\mathrm{q}}^{2}} \leq V_{\max }
$$

By using the dq dynamic voltage equations (1) and (2) of PMA-SynRM and flux equations (4) and (5), and ignoring $R_{\mathrm{s}}$, the steady-state $d q$ voltage equations can be written as follow

$$
V_{\mathrm{s}}=\omega_{\mathrm{m}} n_{\mathrm{p}} \sqrt{\left(L_{\mathrm{q}} i_{\mathrm{q}}+\Psi_{\mathrm{m}}\right)^{2}+\left(L_{\mathrm{d}} i_{\mathrm{d}}\right)^{2}} .
$$

Based on (21), the inverter DC bus voltage is too low to compensate for the back-emf when the base speed is exceeded. The sinusoidal pulse width modulation technique was used in this study. Therefore, the maximum voltage $V_{\max }$ is

$$
V_{\max }=\frac{1}{2} V_{\mathrm{BUS}} K_{v}
$$

where $K_{\mathrm{v}}<1$ is a security gain, which assures that the ceiling voltage is not reached.

$$
\begin{array}{r}
\omega^{*} \leq 0: i_{\alpha} \\
\omega^{*}<0: \quad i_{\alpha}-1 .
\end{array}
$$

A PI controller is utilized in order to guarantee that the error converges to zero. Its design and stability are going to be explained in the next section. The controller output is limited between negative value and zero. The final value $i_{\alpha}$ must be divided into two conditions to assure the four-quadrant of the field-weakening control.

2.5 Controller design and stability of the proposed control scheme

$$
\begin{aligned}
G_{\mathrm{old}} & =\frac{K_{\mathrm{pd}}}{R_{\mathrm{s}}} \frac{s \tau_{\mathrm{i} d}+1}{s \tau_{\mathrm{i} d}\left(s \tau_{\mathrm{s} d}+1\right)}, \\
G_{\mathrm{olq}} & =\frac{K_{\mathrm{pq}}}{R_{\mathrm{s}}} \frac{s \tau_{\mathrm{i} q}+1}{s \tau_{\mathrm{i} q}\left(s \tau_{\mathrm{s} q}+1\right)},
\end{aligned}
$$

$\tau_{\mathrm{sd}}=L_{\mathrm{d}} / R_{\mathrm{s}}, \tau_{\mathrm{sq}}=L_{\mathrm{q}} / R_{\mathrm{s}}$ are the electrical time constant of the $d$-axis and $q$-axis, $K_{\mathrm{pd}}, K_{\mathrm{pq}}$ are the proportional gain of the $d$-axis and $q$-axis controller, $\tau_{\text {id }}, \tau_{\text {iq }}$ are the time constant of the $d$-axis and $q$-axis current loop.

The two current loops are much faster than the speed loop. Therefore, the PI current controllers are tuned first. By subtracting the back-emf term of the voltage equations (1) and (2), the two currents $i_{\mathrm{d}}$ and $i_{\mathrm{q}}$ can be controlled independently. The open-loop transfer functions of the $i_{\mathrm{d}}$ and $i_{\mathrm{q}}$ currents can be expressed, as shown in (24) and (25).

By using pole-zero cancellation [21], that is, $\tau_{s d}=\tau_{i_{\mathrm{d}}}$ and $\tau_{s q}=i_{\mathrm{q}}$, the controller parameters can be obtained

$$
\begin{array}{ll}
K_{\mathrm{pd}}=\omega_{\mathrm{cd}} L_{\mathrm{d}}, & K_{\mathrm{id}}=\omega_{\mathrm{cd}} R_{\mathrm{s}}, \\
K_{\mathrm{pq}}=\omega_{\mathrm{cq}} L_{\mathrm{q}}, & K_{\mathrm{iq}}=\omega_{\mathrm{cq}} R_{\mathrm{s}},
\end{array}
$$

where $\omega_{\mathrm{cd}}$ is the $d$-axis crossover frequency and $\omega_{\mathrm{cq}}$ is the $q$-axis crossover frequency.

The open-loop transfer function of the speed control is

$$
G_{0 \omega}=K_{\mathrm{p} \omega} \frac{s \tau_{\mathrm{i} \omega}+1}{s \tau_{\mathrm{i} \omega}\left(s \tau_{\mathrm{s} \omega}+1\right)}
$$

where $\tau_{\mathrm{s} \omega}=J / B_{\mathrm{f}}$ is the electrical time constant of the $d$-axis, $J$ is the inertia, $B_{\mathrm{f}}$ is the viscous friction, $K_{\mathrm{p} \omega}$ is the proportional gain of the speed controller, and $\tau_{\mathrm{i} \omega}$ is the time constant speed loop.

By using pole-zero cancellation, that is, $\tau_{\mathrm{s} \omega}=\tau_{\mathrm{i} \omega}$, the speed controller parameters can be obtained

$$
K_{\mathrm{p} \omega}=\frac{9 J}{\tau_{\mathrm{r} \omega}}, \quad K_{\mathrm{i} \omega}=\frac{K_{\mathrm{p} \omega}}{\tau_{\mathrm{s} \omega}}
$$

where $\tau_{\mathrm{r} \omega}$ is the closed-loop response time, which can be obtained from the desired speed response.

Finally, the field-weakening controller is analyzed by considering the stator voltage equation (21). The fieldweakening stability is satisfied when its time constant is lower than the two-current control loop and lower than or equal to the speed control loop. Note that the crossover frequency of each control loop is discussed in Fig. 8 in which $\omega_{\mathrm{s}}, \omega_{\mathrm{i}}$, and $\omega_{\text {? }}$ are the constant switching of the PWM strategy of $16 \mathrm{kHz}\left(100531 \mathrm{rad} \mathrm{s}^{-1}\right)$, the crossover frequency of the current control loop is $69.8132 \mathrm{rads}^{-1}$, and the crossover frequency of the speed control loop is $9.97 \mathrm{rad} \mathrm{s}^{-1}$, respectively.

\section{Simulation and experimental validation}

\subsection{Test bench setup and PMA-SynRM control parame- ters}

Tables 1 and 2 list the main parameters of the PMASynRM, and Table 3 illustrates the controller parameters. The PMA-SynRM was fed using a $3 \mathrm{~kW} 3-\Phi$ DC-AC voltage source inverter (VSI) operated at a switching frequency of $16 \mathrm{kHz}$. The speed and rotor angle measurements were performed with a resolver on the rotor shaft.

\subsection{Dynamic performance of proposed field-weakening}

To validate that the controller is appropriately designed, a simulation of the controller was developed employing MATLAB/SIMULINK software. Figure 9 shows the simulation results and Fig. 10 shows the experimental results. Ch1 is the speed command $n_{\mathrm{COM}}, \mathrm{Ch} 2$ is the $q$-axis current $i_{\mathrm{q}}, \mathrm{Ch} 3$ is the $d$-axis current $i_{\mathrm{d}}, \mathrm{Ch} 4$ is the measured speed $n, \mathrm{Ch} 5$ is $V_{\max }, \mathrm{Ch} 6$ is the $d$-axis voltage $V_{\mathrm{d}}$, Ch7 is the $q$-axis voltage $V_{\mathrm{q}}$, Ch8 is the stator voltage $V_{\mathrm{s}}, \mathrm{Ch} 9$ is $i_{\alpha}, \mathrm{Ch} 10$ is the $q$-axis current $i_{\mathrm{q}}$, and Ch12 is the stator current $i_{\mathrm{A}}$. As shown in Figs. 9 and 10, the speed reference changes from 0 to $2000 \mathrm{rpm}$, which includes the transition between the 

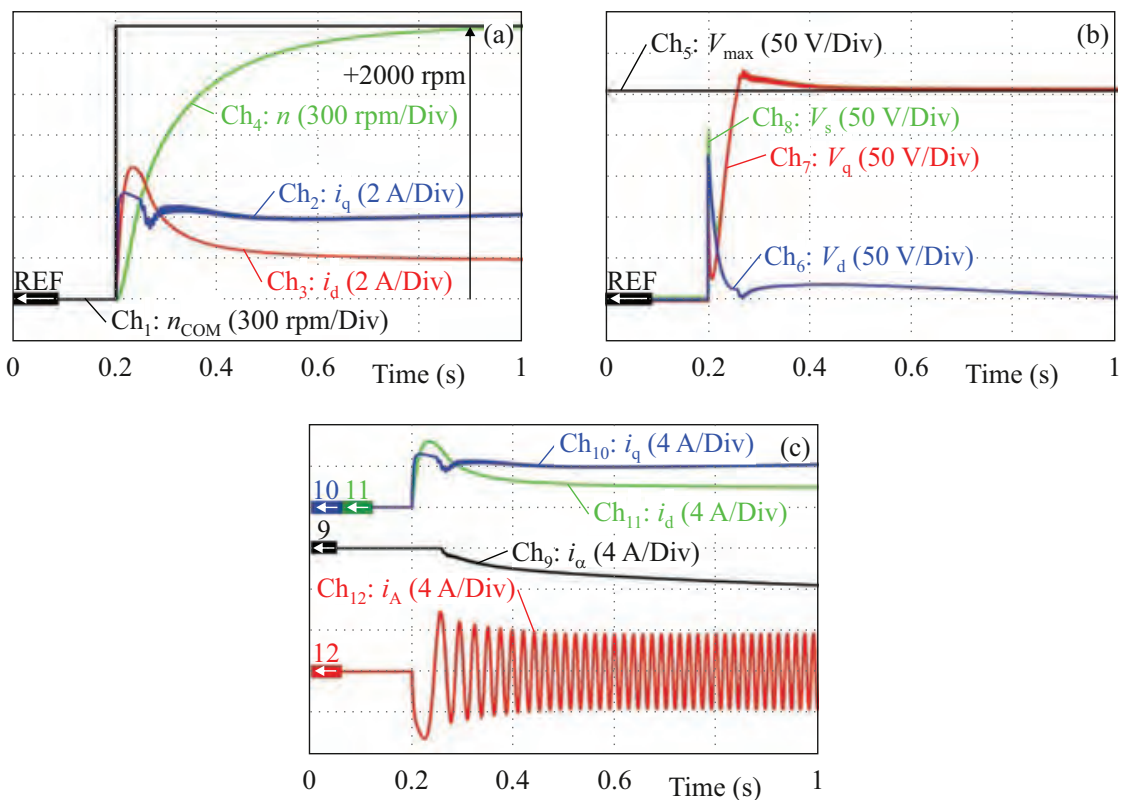

Fig. 9. Simulation results: dynamic performance of the proposed field-weakening control
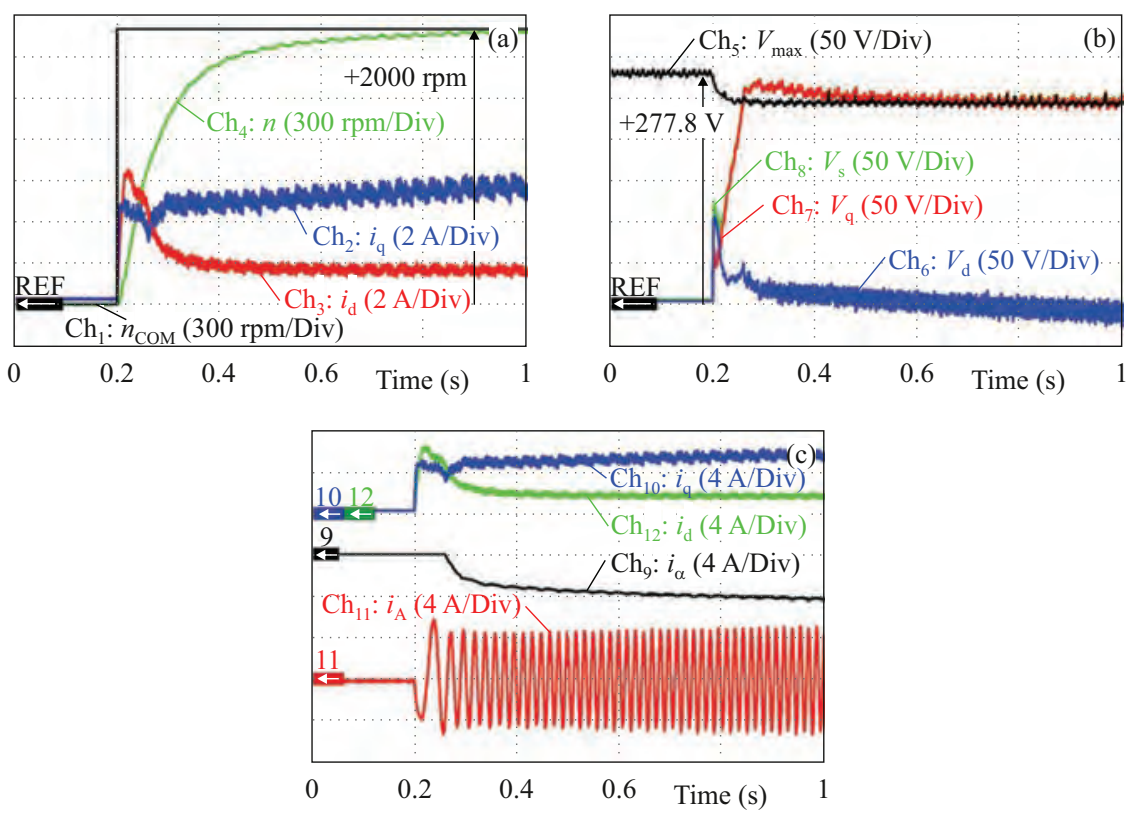

Fig. 10. Experimental results: dynamic performance of the proposed field-weakening control

constant torque and constant power mode. The machine works well, with full performance under constant torque and constant power operations in both directions of the speed as well as torque.

The results show that the actual speed matches the reference speed. Both the $i_{\mathrm{d}}$ and $i_{\mathrm{q}}$ experimental results correspond to the simulation results. Both figures correspond to each other. When $V_{\mathrm{s}}$ reaches $V_{\max }$, the field-weakening operation is activated. The output of the PI compensator increases id into the negative direction. The transition between the constant torque and constant power regions is fast and smooth under all operating conditions.

\subsection{Dynamic performance of the proposed MTPA}

Figure 11 represents the dynamic performance test under the four-quadrant operation of the PMA-SynRM in the constant torque region. The test was performed to validate the proposed MTPA algorithm. Ch1 is the speed reference $n_{\mathrm{REF}}, \mathrm{Ch} 2$ is $i_{\mathrm{d}}, \mathrm{Ch} 3$ is $i_{\mathrm{q}}, \mathrm{Ch} 4$ is the measured speed $n$, Ch5 is $V_{\max 4}$, Ch6 is $V_{\mathrm{d}}, \mathrm{Ch} 7$ is $V_{\mathrm{q}}, \mathrm{Ch} 8$ is $V_{\mathrm{s}}$, Ch9 is the torque reference $T_{\mathrm{eREF}}$, Ch10 is the phase current $i_{A}$, and Ch11 is the measured torque $T_{\text {meas }}$. The 

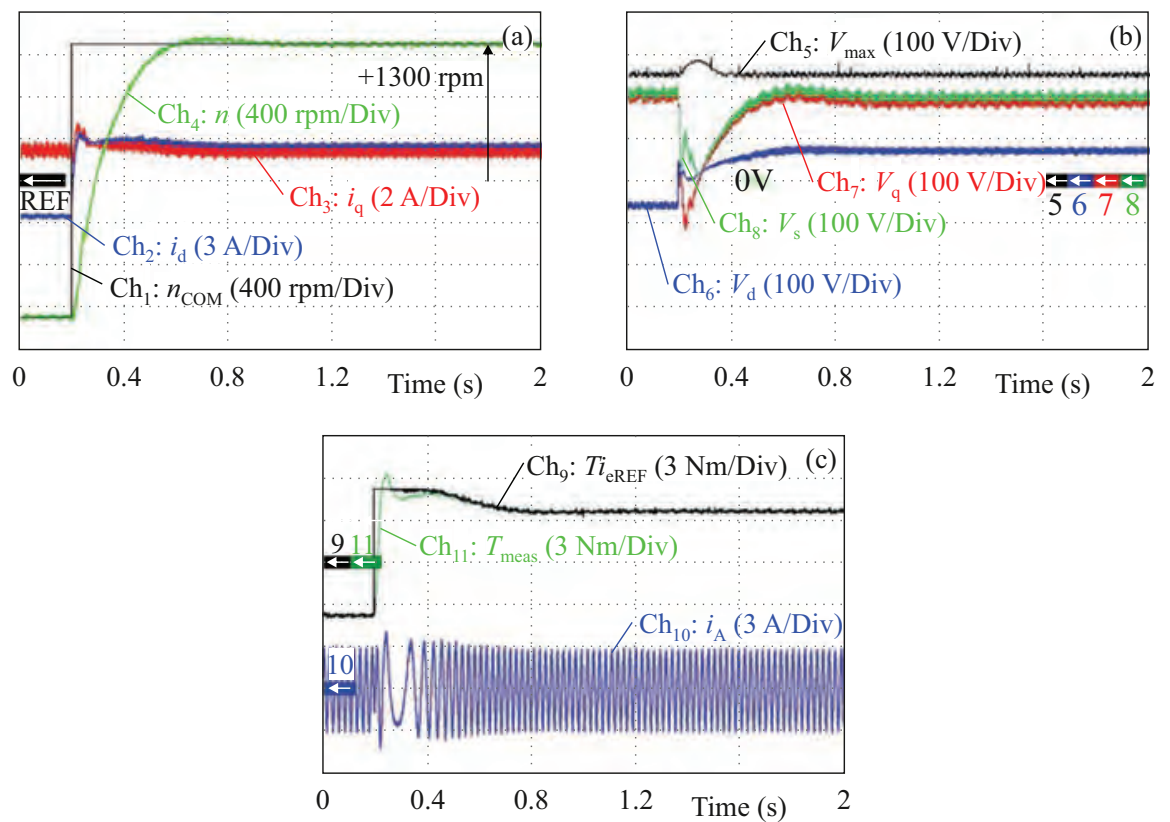

Fig. 11. Experimental results: dynamic performance during constant torque operation
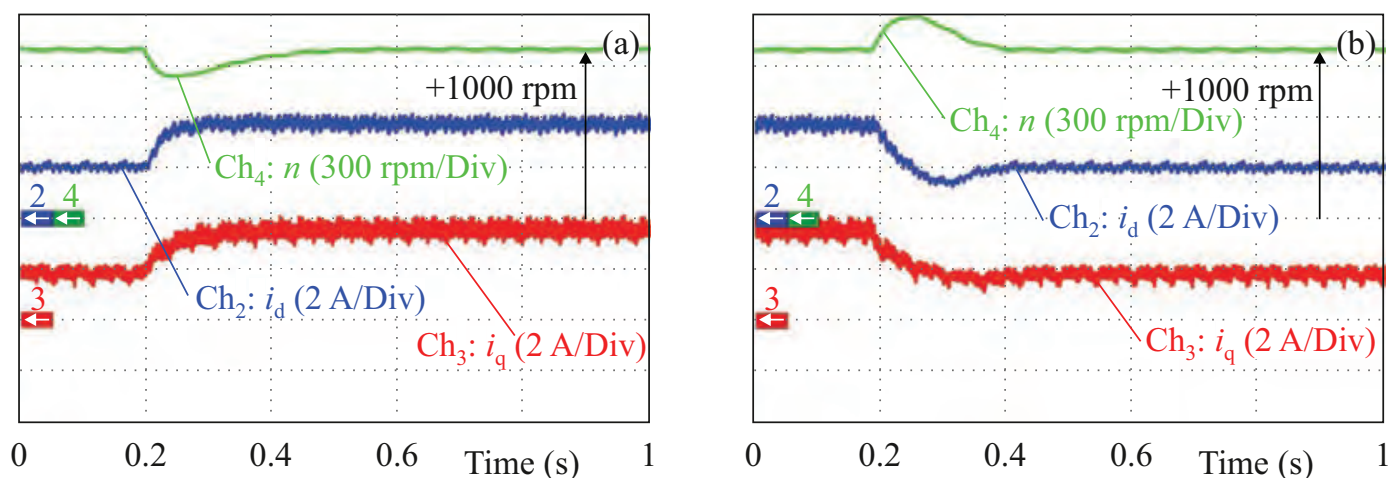

Fig. 12. Experimental results: dynamic performance of the disturbance rejection, (a) - on load, (b) - off load

Table 2. PMA-SynnRM/inverter specification and parameters

\begin{tabular}{lcc}
\hline Symbol & Meaning & Value \\
\hline$P_{\text {rated }}$ & Rated power & $1 \mathrm{~kW}$ \\
$n_{\text {rated }}$ & Rated speed & $1350 \mathrm{rpm}$ \\
$T_{\text {rated }}$ & Rated torque & $7.07 \mathrm{Nm}$ \\
$i_{\text {rated }}$ & Rated current & $5.4 \mathrm{~A}$ \\
$P F$ & Power factor & 0.80 \\
$p$ & Number of pole pairs & 2 \\
$R_{\mathrm{s}}$ & Resistance* & $3.2 \Omega$ \\
$J$ & Equivalent inertia & $0.0017 \mathrm{~kg} \mathrm{~m}{ }^{2}$ \\
$B$ & Viscous friction coefficient & $0.0027 \mathrm{Nm} \mathrm{s} / \mathrm{rad}$ \\
$f_{\mathrm{s}}$ & Switching frequency & $16 \mathrm{kHz}$ \\
\hline$*($ motor + inverter $)$ &
\end{tabular}

speed reference changes from -1300 to $1300 \mathrm{rpm}$. The measured speed matches the reference. The $d$ - and $q$-axes currents are optimized based on the MTPA curve, as
Table 3. Speed/current and field-weakening regulation parameters

\begin{tabular}{lcc}
\hline Symbol & Meaning & Value \\
\hline$K_{\mathrm{pq}}$ & $q$-axis current proportional gain & 19.2 \\
$K_{\mathrm{iq}}$ & $q$-axis current integral gain & $1.5015 \times 10^{3}$ \\
\hline$K_{\mathrm{pd}}$ & $d$-axis current \\
& proportional gain & 19.2 \\
\hline$K_{\mathrm{id}}$ & $d$-axis current integral gain & $1.2243 \times 10^{3}$ \\
$K_{\mathrm{pw}}$ & Speed proportional gain & 0.2 \\
$K_{\mathrm{iw}}$ & Speed integral gain & 2 \\
\hline$K_{\mathrm{pfw}}$ & Field-weakening \\
\hline$K_{\mathrm{ifw}}$ & proportional gain & 0.2 \\
$I_{\mathrm{smax}}$ & Mield-weakening integral gain \\
$i_{\mathrm{smin}}$ & Minimum quadrature current & 2 \\
$V_{\mathrm{dc}}$ & DC bus voltage & $+5.4 \mathrm{~A}$ \\
\hline & & $-5.4 \mathrm{~A}$ \\
& & $400 \mathrm{~V}$ \\
\hline
\end{tabular}

shown in Fig. 5. The results show that the PMA-SynRM operates in the constant torque region because $V_{\mathrm{s}}$ is lower than $V_{\max }$. The machine operates well, with full perfor- 
mance in this region. The measured torque matches the reference torque. The results reflect that the machine operates under the conditions described in (17).

\subsection{Dynamic performance of disturbance rejection}

In Fig. $12(\mathrm{a}), \mathrm{Ch} 2$ is the $d$-axis current $i_{\mathrm{d}}, \mathrm{Ch} 3$ is the $q$-axis current $i_{\mathrm{q}}$, and Ch4 is the measured speed $n$ when the load is added suddenly. In Fig. 12(b), Ch2 is the $d$-axis current $i_{\mathrm{d}}$, Ch3 is the $q$-axis current $i_{\mathrm{q}}$, and Ch4 is the measured speed $n$ when the load is suddenly removed. It can be verified that the controller has a fast, transient response and a small steady-state error as well as an appropriate regulation capability when the load torque is varied. The recovery time of speed is $\approx 0.2$.

\section{Conclusions}

This paper presents the control system based on the MTPA to minimize the copper losses and field-weakening control of the PMA-SynRM. The proposed MTPA was considered regarding the copper loss and electromagnetic torque equations to identify the optimized d- and q-axis reference current curves, and they are stored in the lookups. By utilizing the proposed field weakening control, the machine can operate in both the constant torque and constant power regions. The simulation results show that the copper losses with the MTPA algorithm are lower than those without the MTPA algorithm of $\sim 10 \%$. Finally, the PMA-SynRM, which was designed and implemented for testing in the laboratory, has a high performance. The PMA-SynRM operates above the base speed of $\sim 70 \%$ in the constant power region by mean of the proposed field weakening control. It was shown that the uncontrolled generator mode running, which occurs in the high-speed operation of the conventional PM motor drives, can be eliminated in PMA-SynRM. It is suitable for the use in electric vehicle traction instead of high-cost permanent machines such as IPMSM. This machine has the capability required for the traction systems of EVs and HEVs. However, its linear control system must be improved such that high performance can be obtained under all conditions.

\section{Acknowledgments}

A research program partially supported this work in cooperation with the Faculty of Technical Education and Thai French Innovation Institute, King Mongkut'is University of Technology North Bangkok, and Université de Lorraine (Grant No. KMUTNB-61-GOV-D-68).

\section{REFERENCES}

[1] C. Ogbuka, C. Nwosu, and M. Agu, "A Fast Hysteresis Current-Controlled Permanent Magnet Synchronous Motor Drive Based on Field Orientation", Journal of Electrical Engineering, vol. 67 , no. 2 , pp. $69-77,2016$.
[2] V. Sarac, "Performance Optimization of Permanent Magnet Synchronous Motor by Cogging Torque Reduction", Journal of Electrical Engineering, vol. 70, no. 3, pp. 218-226, 2019.

[3] S. Ooi, S. Morimoto, M. Sanada, and Y. Inoue, "Performance Evaluation of a High-Power-Density PMASynRM with Ferrite Magnets", IEEE Transactions on Industry Applications, vol. 49, no. 3, pp. 1308-1315, 2013.

[4] S. Morimoto, S. Ooi, Y. Inoue, and M. Sanada, "Experimental Evaluation of a Rare-Earth-Free PMASynRM With Ferrite Magnets for Automotive Applications", IEEE Transactions on Industrial Electronics, vol. 61, no. 10, pp. 5749-5756, 2014.

[5] S. Morimoto, M. Sanada, and Y. Takeda, "Performance of PM-Assisted Synchronous Reluctance Motor for High-Efficiency and Wide Constant-Power Operation", IEEE Transactions on Industry Applications, vol. 37, no. 5, pp. 1234-1240, 2001.

[6] G. Park, J. Kim, B. Son, and S. Jung, "Optimal Design of PMa-synRM for an Electric Propulsion System Considering Wide Operation Range and Demagnetization", IEEE Transactions on Applied Superconductivity, vol. 28, no. 3, pp. 1-4, 2018.

[7] I. Boldea, L. Tutelea, and C. Pitic, "PM-Assisted Reluctance Synchronous Motor/Generator (PM-RSM) for Mild Hybrid Vehicles:Electromagnetic Design", IEEE Transactions on Industry Applications, vol. 40, no. 2, pp. 492-498, 2004.

[8] A. Tessarolo, "Accurate Computation of Multiphase Synchronous Machine Inductances Based on Winding Function Theory", IEEE Transactions on Energy Conversion, vol. 27, no. 4, pp. 895-904, 2012.

[9] O. Payza, Y. Demir, and M. Aydin, "Investigation of Losses for a Concentrated Winding High-Speed Permanent Magnet-Assisted Synchronous Reluctance Motor for Washing Machine Application", IEEE Transactions on Magnetics, vol. 54, no. 11, pp. 1-5, 2018.

[10] M. Barcaro, N. Bianchi, and F. Magnussen, "Permanent-Magnet Optimization in Permanent-Magnet-Assisted Synchronous Reluctance Motor for a Wide Constant-Power Speed Range", IEEE Transactions on Industrial Electronics, vol. 59, no. 6, pp. 2495-2502, 2012.

[11] H. Huang, Y. Hu, Y. Xiao, and H. Lyu, "Research of Parameters and Antidemagnetization of Rare-Earth-Less Permanent Magnet-Assisted Synchronous Reluctance Motor", IEEE Transactions on Magnetics, vol. 51, no. 11, pp. 1-4, 2015.

12] M. Islam, A. Arafat, S. Bonthu, and S. Choi, "Design of a Robust Five-Phase Ferrite-Assisted Synchronous Reluctance Motor with Low Demagnetization and Mechanical Deformation", IEEE Transactions on Energy Conversion, vol. 34, no. 2, pp. 722-730, 2019.

13] M. Obata, S. Morimoto, M. Sanada, and Y. Inoue, "Performance of PMASynRM with Ferrite Magnets for EV/HEV Applications Considering Productivity", IEEE Transactions on Industry Applications, vol. 50, no. 4, pp. 2427-2435, 2014.

[14] I. Bodea et al, "DTFC-SVM Motion-Sensorless Control of a PM-Assisted Reluctance Synchronous Machine as Starter-Alternator for Hybrid Electric Vehicles", IEEE Transactions on Power Electronics, vol. 21, no. 3, pp. 711-719, 2006.

[15] P. Thounthong, S, Sikkabut, N. Poonnoy, P. Mungporn, B. Yodwong, P. Kumam, N. Bizon, B. Nahid-Mobarakeh, and S. Pierfederici, "Nonlinear Differential Flatness-Based Speed/ Torque Control With State-Observers of Permanent Magnet Synchronous Motor Drives", IEEE Transactions on Industry Applications, vol. 54, no. 3, pp. 2874-2884, 2018.

[16] E. Trancho, E. Ibarra, A. Arias, I. Kortabarria, J. Jurgens, L. Marengo, A. Fricass, and J. V. Gragger, "PM-Assisted Synchronous Reluctance Machine Flux Weakening Control for EV and HEV Applications", IEEE Transactions on Industrial Electronics, vol. 65, no. 4, pp. 2986-2995, 2018.

17] B. Kerdsup, N. Takorabet, and B. Nahidmobarakeh, "Design of Permanent Magnet-Assisted Synchronous Reluctance Motors with Maximum Efficiency-Power Factor and Torque per Cost", 
in XIII International Conference on Electrical Machines (ICEM) 2018.

[18] J. K. Author, "Etude et optimisation de machines à aimants permanents à démarrage direct sur le réseau", $P h D$ dissertation, UL. Département de Formation Doctorale -Electronique et Electrotechnique, Docteur de l'Université Henri Poincaré, Nancy, France, 2011.

[19] J.-M. Kim and S.-K. Sul, "Speed Control of Interior Permanent Magnet Synchronous Motor Drive for the Flux Weakening Operation", IEEE Transactions on Industry Applications, vol. 33, no. 1, pp. 43-48, 1997.

[20] P.-Y. Lin and Y.-S. Lai, "Voltage Control Technique for the Extension of DC-Link Voltage Utilization of Finite-Speed SPMSM Drives", IEEE Transactions on Industrial Electronics, vol. 59, no. 9, pp. 3392-3402, 2012.

[21] S. Lee, "Closed-Loop Estimation of Permanent Magnet Synchronous Motor Parameters by PI Controller Gain Tuning", IEEE Transactions on Energy Conversion, vol. 21, no. 4, pp. 863-870, 2006

Received 10 December 2019

Babak Nahid-Mobarakeh received the $\mathrm{PhD}$ degree in electrical engineering from the Institut National Polytechnique de Lorraine (INPL), Nancy, France, in 2001. From 2001 to 2006, he was at the Centre de Robotique, Electrotechnique et Automatique, University of Picardie, Amiens, France. In September 2006, he joined the Ecole Nationale Superieured' Electricite et de Mecanique, Université de Lorraine, Nancy, where he is currently a Full Professor. He is the author or coauthor of more than 200 international peer-reviewed journal and conference papers, as well as several book chapters. He has been the recipient of several IEEE awards. He was the General co-chair of the 2015 IEEE Transportation Electrification Conference and Expo (ITEC). Currently, he is the Chair of the Industrial Automation and Control Committee (IACC) of the IEEE Industry Applications Society (IAS). He serves as the Committee Administrator and the Technical Committee Paper Review Chair. His main research interests include nonlinear and robust control design of power converters and drives, fault detection and fault-tolerant control of electric systems, and design, control and stabilization of microgrids.

Noureddine Takorabet received the Engineering degree from the Ecole Nationale Polytechnique d'Alger, El Harrach, Algeria, in 1993, the Master's degree in electrical engineering from the University Nancy I, Nancy, France, in 1994, and the $\mathrm{PhD}$ degree from the Université de Lorraine, Nancy, France, in 1996. He is currently a Professor with the Université de Lorraine, where he is a member of the Groupe de Recherche en Électrotechnique et en Électronique de Nancy (GREEN), École Nationale Supérieure d'Électricité et de Mécanique, Institut National Polytechnique de Lorraine. His teaching activities concern electrical machines, electromagnetics, and the numerical simulation and design of electromagnetic devices. His main research activities include the modeling and optimization of electromagnetic devices, particularly electromechanical conversion.

Serge Pierfederici received the engineering degree from the 'Ecole Nationale Supérieured' Electricité et Mécanique',
Nancy-Lorraine, France, in 1994, and the PhD degree in electrical engineering from the Institut National Polytechnique de Lorraine in 1998. Since 2009, he is a full professor at the Université de Lorraine, Nancy. He is the authors or co-authors, or more than 200 international peers reviewed journals, and has been the recipient of several IEEE awards. His research interests include the stability study of distributed power systems, the modeling, and control of power electronic systems and in recent years, the distributed control of multi-sources multi-carrier microgrids.

Poom Kumam received the BS degree in mathematics from Burapha University (BUU), and an MSc degree in mathematics from Chiang Mai University (CMU), and a PhD degree in mathematics from Naresuan University (NU) in 2007. In 2008, he received a grant from Franco-Thai Cooperation for short-term research at Laboratoire de Mathématiques, Université de Bretagne Occidentale, France. In 2012, he took the same role, a Visiting Professor at the University of Alberta, $\mathrm{AB}$, Canada, for short research two months with professor Anthony To-Ming Lau. Since 2015, he is a full professor at the Department of Mathematics at King Mongkut's University of Technology Thonburi (KMUTT). His research interests include fixed point theory and applications, computational optimization algorithms, nonlinear optimization, and control theory, and his research interest focuses on fixed-point theory related to optimization problems in both pure science and applied science. He has published or presented over 400 scientific papers and projects.

Nicu Bizon was born in Albesti de Muscel, Arges county, Romania, 1961. He received a BS degree in electronic engineering from the University "Polytechnic" of Bucharest, Romania, in 1986, and the PhD degree in Automatic Systems and Control from the same university in 1996. From 1996 to 1989, he was in hardware design with the Dacia Renault SA, Romania. He is currently a professor at the University of Pitesti, Romania. He received in 2013 and 2016 two awards from Romanian Academy. He is an editor of eight books and more than 400 papers in scientific fields related to Energy, which is his current research interest.

Phatiphat Thounthong was born in Phatthalung, Thailand, on December 29, 1974. He received the BS and ME degrees in electrical engineering from King Mongkut's Institute of Technology North Bangkok (KMITNB), Bangkok, Thailand, in 1996 and 2001, respectively, and the $\mathrm{PhD}$ degree in electrical engineering from Institut National Polytechnique de Lorraine (INPL)-Université de Lorraine, Nancy-Lorraine, France, in 2005. Since 2012, he has been a Full Professor in the Department of Teacher Training in Electrical Engineering, King Mongkut's University of Technology North Bangkok. He is the author of 110 scientific papers (including 18 papers in IEEE Transactions/Magazines) published in Scopus with 2403 citations and h-index $=23$. His current research interests include power electronics, electric drives, electric vehicles, electrical devices (fuel cells, photovoltaic, wind turbine, batteries, and supercapacitors), nonlinear controls, and observers. 